DOI 10.37882/2223-2982.2021.04.32

\title{
ЛИНГВОПРАГМАТИЧЕСКИЙ АСПЕКТ ЗАГОЛОВКОВ СЕТЕВЫХ НОВОСТНЫХ СООБЩЕНИЙ АЭРОКОСМИЧЕСКОЙ ТЕМАТИКИ
}

\section{LINGUOPRAGMATIC ASPECT OF THE HEADLINES OF AEROSPACE-RELATED NETWORK NEWS}

\section{A. Trubcheninova}

Summary: The article is devoted to the linguistic and pragmatic features of the headlines of German-language news on aerospace topics. Syntactic models, lexical means and stylistic devices that contribute to the effective implementation of information and influence in the context of Internet communication are identified.

Keywords: online news text, headline, syntactic structure of headline, quantitatives, term, English borrowing, metaphor, colloquial vocabulary.
Трубченинова Анна Александровна

К.филол.н., доцент, Московский авиационный институт (Национальный исследовательский университет) ann-trubcheninova@yandex.ru

Аннотация: Статья посвящена лингвопрагматическим особенностям заголовков немецкоязычных новостных текстов аэрокосмической тематики. Выявлены характерные для заголовков синтаксические модели, лексические средства и стилистические приемы, способствующие эффективной реализации информирования и воздействия в условиях Интернет-коммуникации.

Ключевые слова: сетевой новостной текст, заголовок, синтаксическая структура заголовка, квантитативы, термин, англоязычное заимствование, метафора, разговорная лексика.
$\Phi$ ормируя содержание и структуру современного информационного медиапространства, новостные тексты помогают личности ориентироваться в различных сферах общественной жизни, в том числе и вопросах, связанных со стремительно развивающейся аэрокосмической отраслью. Новостные материалы являются важным источником информации об актуальных событиях в гражданской и военной авиации, о новых технологиях в области авиа- и ракетостроения, а также о космических программах. Названные темы освещаются как в традиционных СМИ, их электронных версиях, так и в сетевых изданиях, отраслевых информационных порталах, группах социальных сетей. Технологические возможности сети Интернет позволяют оперативно обновлять информацию, использовать новые способы ее организации и представления. Сетевые новостные тексты отличает гипертекстовая форма, поликодовость, доступность, интерактивность.

Новостной формат подразумевает направленность текстов на реализацию функции сообщения, стремление к объективности и нейтральному стилю изложения, клишированность языкового оформления. Ориентация на отражение действительности не исключает прагматического воздействия текста на читателя. В процессе получения новых знаний изменяется или корректируется система представлений и мнений реципиента о мире. Воздействие через информирование стало неотъемлемым атрибутом любой новостной информации [3, с.40].

Ключевым элементом новостного сообщения является заголовок - графически выделенное название текста, в сжатом виде представляющее первичную информа- цию о тексте, его содержательные характеристики, модально-временной план. Занимая дотекстовую позицию, заголовок участвует в объемно-прагматическом членении текста, формирует целостность восприятия произведения [4].

В условиях интернет-пространства особо следует выделить информативно-ориентирующую и рекламную роль заголовков. Функционируя относительно самостоятельно в списке доступных публикаций, заголовок участвует в организации гипертекста, «становится не просто частью контента, но и элементом интерфейса» [1, с.17]. Заголовки и подзаголовки представляют собой инструменты навигации, «опорные точки, показывающие важную текстовую информацию» [2, с.159], побуждающие читателя перейти на следующий уровень сайта, где расположен текст сообщения.

В статье рассматриваются структурно-синтаксические модели и лексические средства, задействованные в реализации функций заголовков новостных текстов аэрокосмической тематики. Материалом для исследования послужили заголовки текстов информационного портала dw.com, а также специализированных сайтов flugrevue.de, aerokurier.de, aero.de.

Информативная функция заголовков реализуется за счет структур с разной степенью развернутости, например, односоставных предложений - номинативных конструкций. Их отличает краткость, смысловая емкость, способность сконцентрировать внимание читателя на наиболее важном в информационном плане аспекте сообщения: Die Atomdrohne der CIA (flugrevue.de). Распро- 
странение основных компонентов номинативных заголовков осуществляется за счет употребления предложных групп: Erster Start vom neuen Heimatboden (flugrevue. de); Luftbetankungsversuche mit der $\mathrm{CH}$-53K (flugrevue.de).

Не менее продуктивной синтаксической моделью являются предикативные заголовки в форме двусоставных предложений: Crew-Dragon-Start wird abgebrochen (flugrevue.de). Большинство таких конструкций в роли заголовков представлено распространенными предложениями, так как они дают возможность представить событие более подробно: Letztes ATV verglüht über dem Südpazifik (dw.com). В заголовках практически отсутствуют разного рода обособления и парентезы, линейность модели содействует легкому и однозначному пониманию. Также отметим использование восклицательных конструкций, усиливающих воздействие заголовка на адресата посредством введения субъективного фактора - отношения адресата к событию или факту: Hurra! NASA Raumsonde Cassini lebt! (dw.com) Заголовок привлекает внимание реципиента, способствует созданию положительного эмоционального фона, значимого для осмысления последующего текста.

Использование эллиптических конструкций объясняется способностью последних выражать содержание в сжатой форме. За счет опущения компонентов с меньшей семантической значимостью на первый план выдвигаются элементы с большей коммуникативной нагрузкой. Элиминации подвергаются формы глаголасвязки, в том числе в составе адъективного предиката, а также вспомогательные глаголы как не столь значимые элементы в конструкции заголовка: Endlich Ruhe am Flughafen (dw.com); Erste PD-14 für MS-21 nach Irkutsk geliefert (flugrevue.de). Нередко опускается и сказуемое, которое легко восстанавливается из контекста: Boeing 737 MAX vor Wiederzulassung in Europa (flugrevue.de). Для заголовков осколочного типа с опущением подлежащего характерна большая степень зависимости от содержания текста: Sicher und günstig ins All (flugrevue.de). Смысловая неполнота подобных заголовков компенсируется, как правило, при помощи других элементов заголовочного комплекса, например, надзаголовка, подзаголовка и вводки (лида). Другим типом эллиптических заголовков являются изолированные придаточные предложения, в которых важная роль отводится союзам и местоименным наречиям, определяющим смысл всего предложения: Wie die Triebwerkhersteller der Krise trotzen (flugrevue. de); Was 2021 für die Luftfahrt bedeutet (aero.de). Сформированная посредством такого заголовка «информационная нехватка» побуждает читателя обратиться к тексту сообщения.

Информационная насыщенность и выразительность отличает заголовки - сегментированные конструкции, состоящие из двух частей, соединенных двоеточием.
Первая часть или сегмент является номинативной структурой и обозначает актуальное для пишущего понятие, вторая часть или постсегментный компонент содержит высказывание по поводу понятия, обозначенного в сегменте. В смысловом плане можно выделить следующие типы сегментированных заголовков по характеру их отношения между частями:

технический объект: детали: Rolls-Royce UltraFan: Getriebe-Gigant (flugrevue.de).

событие: детали: Le Bourget: Langstreckenflieger und Kampfjet im Mittelpunkt (dw.com);

проблема/ факт: интерпретация: Absturz im Iran: Mehr Fragen als Antworten (dw.com);

Заголовки содержат, как правило, ключевые слова, отражающие содержание текста и вербализующие наиболее привлекательные для читателя фрагменты информационного потока. В роли ключевых для поиска слов могут выступать как названия моделей летательных аппаратов, авиационного оборудования, ведущих производителей, авиакомпаний, международных авиасалонов, так и словосочетания - репрезентанты актуальных авиационных происшествий.

Неотъемлемым элементом заголовков являются квантитативные элементы, обладающие значительным прагматическим потенциалом. Обозначения количественных данных придают сообщению фактическую точность, достоверность и одновременно воздействуют на читателя, привлекая внимание к объектам исчисления $[5,6]$. Квантитативный смысловой компонент репрезентируется как цифровым способом, так и при помощи лексических средств, среди которых отметим количественные и порядковые числительные, существительные, наречия, глаголы: Ein Fighter, drei Radare (flugrevue. de); China startet erste eigene Mars-Mission (dw.com); Airlines verlieren 2020 über die Hälfte der Passagiererlöse (aero.de); Luftwaffe-A350 fliegt einmal um die Welt (aero.de); American verdoppelt 787-Flotte (flugrevue.de).

Освещение событий в аэрокосмической отрасли, представление результатов научно-технического поиска невозможно без терминов - когнитивно-информационных структур, аккумулирующих специальные знания. Насыщенность терминологической лексикой характерна прежде всего для заголовков специализированных сайтов, ориентированных на подготовленную аудиторию с соответствующей системой фоновых знаний. Использование сложных терминов и терминов-словосочетаний, закрепленных за той или иной тематической областью, способствует более точной передаче информации, позволяет направлять внимание читателя и облегчать восприятие новых данных: Northrop Grumman modernisiert Störbehälter AN/ALQ-131(flugrevue.de); DA50 mit Einziehfahrwerk hebt ab (aerokurier.de); Ariane Works plant wiederverwendbare Erststufe (flugrevue.de). 
Среди терминологических единиц наблюдается большое количество англоязычных заимствований, в том числе и гибридных билингвальных новообразований: Head-up-Displays für Boeing 777X; Airbus zeigt Stealth-Testmodell LOUT (flugrevue.de). Использование англицизмов объясняется отсутствием в немецком языке эквивалентных номинаций для новых понятий, стремлением к языковой экономии. В этой связи важная роль в заголовках отводится англоязычным аббревиатурам обозначениям летательных аппаратов, организаций, технических устройств: VTOL-Flächenflugzeug mit Elektroantrieb (aerokurier.de); Airbus enthüllt Maveric (flugrevue.de); Dreiblatt-Prop erhält EASA-Zulassung (aerokurier.de).

Англоязычные вкрапления, обладающие социальной и культурной престижностью, коммуникативной актуальностью, формируют контраст на уровне языкового кода и являются дополнительным инструментом привлечения внимания читателя: Ein Brite made in Germany (flugrevue.de); Boeings Problemflugzeug 737Max vor dem Comeback (dw.com).

Информативную плотность заголовка увеличивают метафорические номинации, которые выделяют значимые характеристики технического объекта, а также объективируют недоступные для непосредственного наблюдения эмоциональные состояния: Cessna 408 SkyCourier: Cessnas neues Multitool (flugrevue.de); Achterbahn der Gefühle bei Boeing (dw.com). Визуализируя информационное пространство, отсылая к неожиданным материальным образам и процессам, метафоры повышают экспрессивность заголовка и тем самым усиливают его воздействие на читателя: Airbus beerdigt den A380 (dw.com).

Присущая современной медиаречи тенденция к размыванию, смешению традиционных жанров обусловливает использование в новостных заголовках разговорных слов или выражений (фразеологизмов-идиом). Образность последних придает заголовку выразительность и позволяет емко представить конкретную ситуацию: Rolls-Royce legt Ultra-Fan aufs Eis (flugrevue.de). Лексемы разговорного характера, как правило, представляют собой оценочные описания предметов или явлений, формирующие отрицательный эмотивный тон: Loch in der ISS: Sabotage im All oder Schlamperei? (dw.com)

При помощи приемов лексического повтора, аллитерации создаются оригинальные, привлекательные для читателя конструкции, которые оптимизируют восприятие заголовка, усиливают его коммуникативную действенность: Ultraleicht und ultra offen (aerokurier.de); Airlines verharren in der Corona-Starre (aero.de).

Выявленные в ходе исследования синтаксические модели и лексические средства играют ключевую роль в реализации основных коммуникативно-прагматических установок заголовков, превращая их в эффективный инструмент информирования и воздействия в рамках сетевого новостного авиационно-космического дискурса.

\section{ЛИТЕРАТУРА}

1. Варзапова В.Ю. Заголовок сетевого медиатекста как автосемантичный текст // Тенденции развития науки и образования. - № 50 -10. - 2019 - С. 15-18.

2. Лазарева Э.А. Заголовочный комплекс текста - средство организации и оптимизации восприятия // Известия Уральского гос. ун-та. 2006. №40. - С. 158-166.

3. Негрышев А.А. Стандарт и экспрессия в новостном медиатексте: к прагматике композиционной структуры. - МедиаАльманах. 2013. №2 (55). - С.40-45.

4. Прохорова К.В. Заголовочный комплекс медиатекста // Медиалингвистика в терминах и понятиях: словарь-справочник. - М.: Флинта, 2020. - С. 195-201.

5. Симакова С.И. Цифровой контент газетного текста: тенденции развития // Вестник Челябинского гос. ун-та. Сер.: Филология. Искусствоведение. 2011. Вып. 59. №28 (243). - С.90-93.

6. Стеценко Н.М. Особенности содержательно-фактуальной информации в заголовках новостных медиатекстов: прагматический аспект // Вестник ДонНУ. Сер.Б: Гуманитарные науки. - 2016. - №4. - С. 21-26.

() Трубченинова Анна Александровна (ann-trubcheninova@yandex.ru).

Журнал «Современная наука: актуальные проблемы теории и практики» 